From intention to action: A mixed methods study of clients' experiences of goal-oriented practices

\author{
Gina Di Malta \\ University of Roehampton \\ Hanne W. Oddli \\ University of Oslo \\ Mick Cooper \\ University of Roehampton
}

\title{
Acknowledgements
}

Thanks to Adam Gibson, Rubian Lyons, Ezgi Kosar, Terrence Sergeant, and John McLeod, for their contributions to this research. 


\section{From intention to action: A mixed methods study of clients' experiences of goal-oriented practices}

Objectives: Goal-oriented practices are central to many contemporary psychotherapies. The aim of this study was to explore clients' experiences of this work. Design: Mixed methods, with a main qualitative part and a smaller quantitative component. Participants were 22 clients in integrative psychotherapy (15 females, six males, one other). Semi-structured interviews after session 4 and at endpoint were analyzed thematically. Based on identified themes, "goal attitude" scores were developed and their correlations with outcomes investigated. Results: Goal-oriented practices could help clients move from intention to action through increased awareness and focus, setting manageable tasks, and progress monitoring. However, they had the potential to hinder clients' awareness of their intentions, feel irrelevant, disorientating, or demotivating. Effectiveness hinged on client's management of their expectations, flexible working, and time. Positive attitudes towards goal-oriented practices were associated with improvement. Conclusions: Goal-oriented practices can enhance psychotherapeutic work, but need to be individually-tailored and implemented collaboratively.

Keywords: goal, goal setting, psychotherapy, thematic analysis, integrative psychotherapy.

Early psychoanalytic methods focused on uncovering unconscious mental processes, and therefore did not directly enquiry into clients' conscious goals (Cooper \& Law, 2018; Grey et al., 2018). However, with the rise of cognitive and behavioral therapies - in which goal setting and goal utilization played a central role (Grey et al., 2018)—goal-oriented practices became a more common feature of psychotherapy. Today, they are central to a range of problem management and integrative therapies, such as systematic motivational 
counseling (Cox \& Klinger, 2011b) and comprehensive psychotherapy (Grawe, 2004). Goal agreement is also a key component of the working alliance (Bordin, 1979): a central focus across therapies and one of the most robust predictors of therapeutic outcomes (Fluckinger, Del Re, Wampold, \& Horvath, 2018; Zilcha-Mano, 2018). In addition, goal setting is one of the most commonly used techniques in the wider behavioral change field (Epton, Currie, \& Armitage, 2017); and is closely associated with contemporary shared decision-making practices (e.g., The Health Foundation, 2012), in which service users and professionals work together to identify the desired outcomes of the intervention.

Goals can be defined as, "subjectively desirable states of affairs that the individual intends to attain through action" (Kruglanski \& Kopetz, 2009, p. 29). Treatment goals are the particular desired states that an individual hopes to achieve through therapy (Michalak \& Grosse Holtfort, 2006). Goal-oriented practices are those therapeutic activities in which clients' treatment goals are the focus of the psychotherapeutic work (Cooper \& Law, 2018; Law, 2018). This may include a range of activities (Cooper \& Law, 2018). Goal discussion, or metatherapeutic communication about goals (Cooper, Dryden, Martin, \& Papayianni, 2016; Papayianni \& Cooper, 2018), involves the client and therapist collaborative talking about the goals for therapy. Goal setting is, "the process of identifying and establishing goals - generally at the start of therapy" (Cooper \& Law, 2018, p. 3). In goal tracking, the clients' progress towards their goals is monitored, and may involve the use of specific instruments or measures (see, for instance, Cox \& Klinger, 2011a).

In terms of impact, "The beneficial effects of goal setting on task performance is one of the most robust and replicable findings," within the psychological literature (Locke, Shaw, Saari, \& Latham, 1981, p. 145). A recent meta-analysis found an effect size $(d)$ of 0.34 for goal setting on behavior change; with stronger effects for goals that were difficult, set publicly, and group goals (Epton et al., 2017). Feedback on goal progress (i.e., goal tracking) 
has also shown a positive association with goal attainment, with a recent meta-analysis establishing an effect size $\left(d_{+}\right)$of 0.40 (Harkin et al., 2016). Changes in the frequency of feedback were found to mediate this effect, suggesting a direct causal link between goal tracking and goal attainment. As with goal setting, the effects of goal monitoring were also larger when they were physically recorded. Within the psychotherapeutic field, direct evidence of benefit for goal-oriented practices is more limited. However, a recent review of goal measures for psychotherapy found evidence of clinical utility for several of these instruments (Lloyd, Duncan, \& Cooper, 2019), with enhanced levels of engagement when they were used (e.g., McMurran, Cox, Whitham, \& Hedges, 2013) and some evidence that they were associated with greater improvements in therapy (Smith, 1976). Clients also reported that they found these measures helpful (e.g., Cooper et al., 2015).

Within the psychological field, goal setting and monitoring have been shown to enhance outcomes through directing the individual's attention to the identified goal (Locke et al., 1981). A similar process has been hypothesized to take place in psychotherapy (Michalak \& Grosse Holtfort, 2006). Psychological research also indicates that goal setting and monitoring can mobilize effort, support persistence, and motivate people to develop strategies for goal attainment (Locke \& Latham, 2002; Locke et al., 1981). However, these processes have not been evidenced within a psychotherapeutic context.

Several additional causal mechanisms have been proposed for why goal-oriented practices may be helpful for psychotherapy. First, they may help therapists and clients to establish realistic treatment expectations (Smith, 1994), and these have been associated with more positive therapeutic outcomes (Snyder, Michael, \& Cheavens, 1999). Second, they may help to foster agreement and cooperation between therapists and clients (Smith, 1994), particularly regarding the goals of therapy. Third, goal-oriented practices may increase 
clients' feelings of hope, empowerment, and self-worth by "positioning" them as agentic, intelligible beings, with the potential to act upon their worlds (Mackrill, 2010).

Within the psychotherapeutic literature, a range of challenges to goal-oriented practices have also been posited. Most commonly, it has been argued that such practices may be of limited therapeutic benefit, and potentially counter-therapeutic, as clients may not know what their "real" goals are (Cooper \& Law, 2018). This argument is supported by evidence that goals can exist, and influence behavior, at an unconscious level (Bargh, Gollwitzer, LeeChai, Barndollar, \& Trötschel, 2001). It is also supported by research showing that individuals" "self-attributed motives" (as assessed, for instance, by self-report instruments) have only a small degree of association with their "implicit motives" (as assessed, for instance, by projective tests; Spangler, 1992). Hence, there is the potential that explicit goaloriented practices may divert clients from deeper, more fundamental concerns. Consistent with this, Oddli, McLeod, Reichelt, and Rønnestad (2014) found that explicit goal agreement was not present in the psychotherapeutic work of experienced, high alliance psychotherapists. In this respect, methods such as "plan formulation" (Silberschatz, 2017) may be seen as more sophisticated and meaningful tools for capturing the unconscious, unarticulated aspects of clients' goals. Goal-oriented practices have also been criticized for promoting a mechanistic approach to psychotherapy; and for reinforcing clients' "extrinsic" desires - to achieve and "do"-rather than facilitating a more salutogenic state of "being" (Rowan, 2008).

Within the psychotherapeutic literature, a range of factors have also been proposed that may enhance the value of goal-oriented practices. A consistent emphasis is on the importance of collaboration in goal discussion and goal setting, whereby therapists work to ensure that clients are fully engaged in the process (Feltham, Martin, Walker, \& Harris, 2018; Law, 2018; Grosse Holtforth \& Castonguay, 2005). It has also been argued that goaloriented practices should be conducted flexibly (Feltham et al., 2018): for instance, allowing 
clients to shift to an "off-goal" topic if it becomes pressing. Closely related to this, it has been proposed that, while goals should be set at the beginning of therapy, they should also be negotiated continually during the course of therapy (Michalak \& Grosse Holtfort, 2006). This contrasts with a "set and forget" process, in which goals are required to remain consistent irrespective of changes in the client's life (Feltham et al., 2018). Within much of the psychotherapeutic literature on goals, there is also an emphasis on setting "small steps" (Cox \& Klinger, 2011b; Michalak \& Grosse Holtforth, 2006; Snyder \& Taylor, 2000). These are realistic, relatively achievable goals that can help the client build their sense of selfefficacy over time.

While there is some acknowledgement that goal-oriented practices may be of more or less value to individual clients (Cooper, 2018), no specific moderators (e.g., gender) have been researched or proposed. It is also unclear what the implications of a positive or negative attitude towards goal-oriented practices might be: for instance, in terms of clinical outcomes.

To date, another major limitation of the field is a lack of any over-arching theoretical framework by which to draw together findings and hypotheses regarding goal-oriented practices in psychotherapy. Such a framework may be of particular importance to this field, where there is a need to consider both explicit goal-oriented behaviors and also more complex — and potentially unconscious - desires and motivations. Recently, however, Cooper (2019) has proposed that goal-oriented practices can be understood within the context of a broader directional arc. This draws on Prochaska and DiClemente's (1986) "stages of change", Heckhausen and Gollwitzer's (1987) “Rubicon model” of action phases, and Grawe's (2004) application of these models to practice, to suggest that human beings' agentic, forward-moving strivings can be conceptualized in terms of eight overlapping phases: “emergence”, “awareness”, “evaluation”, “intention”, “planning”, “action”, "feedback", and "termination". For Cooper, psychological wellbeing is synonymous with the 
actualization of directions through these phases. Hence, he suggests that explicit goaloriented practices will be helpful or unhelpful to the extent that they facilitate, or block, movement through particular phases of this arc. Specifically, he writes:

From the perspective of a directional framework, goals may be particularly useful for clients who are already at the intentional phase of the directional arc: clients who have a sense of what they want but need the motivation and focus to move into planning and action. On the other hand, clients who are at — or want to stay within - the awareness and evaluation phases may have less need for specific goal-oriented practices. (p. 204)

The aim of this research, therefore, was to conduct the first in-depth investigation into clients' experiences of goal-oriented work in psychotherapy. We wanted to know how clients experienced these practices, including what they found helpful and unhelpful in this work. We also wanted to explore whether any statistical associations existed between clients' attitudes to goal-oriented practices and their demographic or clinical features. Finally, we were interested to see whether the identified benefits and disbenefits of goal-oriented practices could be located within a broader theoretical framework, such as Cooper's (2019) directional arc.

\section{Methods}

The Project was submitted under ethical considerations of the University of Roehampton's ethics committee and approved on 25-06-2015 under the reference PSYC 15/ 169. 


\section{Design}

We adopted a mixed methods approach (Creswell, 2014). The main element was an exploratory qualitative investigation, based on interviews at two time points. In addition, we conducted a smaller quantitative component, which explored the correlates of participants' attitudes to goal-oriented practices.

\section{Participants}

The research was conducted at a free university psychotherapy research clinic, which offered up to 24 sessions of pluralistic therapy for depression. Inclusion criteria were being 18 years old or over, and having a Patient Health Questionnaire-9 score consistent with a diagnosis of depression (PHQ-9 $\geq 10$, Kroenke, Spitzer, \& Williams, 2001). Exclusion criteria were severe mental health conditions, including individuals experiencing psychosis, severe personality disorders, or drug and alcohol addictions.

There were 22 clients who participated in the study. This was $78.6 \%$ of all 28 clients who were assessed by the clinic between the $28^{\text {th }}$ Jan 2016 and the $8^{\text {th }}$ November 2017, and met criteria for inclusion in the study. Of the six clients who did not take part in this study, one dropped out of psychotherapy prior to the scheduled interview, and five others failed to attend interview meetings.

Seventeen of the 22 clients were referred from the university's wellbeing service (77.3\%), and five were members of the local community (22.7\%). Fifteen of the clients identified as female (68.1\%), six as male (33.3\%), and one as other (4.5\%). Ages ranged from 18 to 57 years old, with a mean age of 24.6 years old $(S D=8.5)$. In terms of ethnicity, 18 clients identified as White British, three as any Other White background, and one as African. On average clients had 19.5 sessions of psychotherapy $(S D=5.1)$; with 15 clients having a planned ending (68.2\%), and seven clients having an unplanned ending (31.8\%). 
At baseline assessment, the 22 clients had a mean score of $19.2(S D=4.3)$ on the PHQ-9 (Kroenke et al., 2001), which is in the moderately severe depression range. Their mean score on the GAD-7 measure of anxiety was $14.7(S D=4.6)$ (Spitzer, Kroenke, Williams, \& Löwe, 2006), which is in the moderately severe anxiety range. At endpoint, 12 of the clients (54.5\%) had shown reliable improvement on the PHQ-9 and 11 (50\%) had shown reliable improvement on the GAD-7, with one client showing reliable deterioration on the GAD-7 (4.5\%). Reliable change is improvement or deterioration that is unlikely to be due to measurement error, and on the PHQ-9 has been defined as a movement of 6 points or more (Gyani, Shafran, Layard, \& Clark, 2013).

The 22 clients were seen by a team of eight psychotherapists, who saw between one and six clients (median $=2$ clients). Five of the psychotherapists were female and two were male; three identified as White British and four as Other White European. Four of the psychotherapists were fully qualified, and three were trainees on a doctoral program in counselling psychology in the final, or penultimate, year of their studies. Demographic data on one therapist were unavailable. Typically, the psychotherapists had been trained in person-centered, psychodynamic, and cognitive-behavioral treatment methods; and, in the present study, were instructed to practice pluralistically (see below): drawing on these methods as appropriate to their clients' particular preferences and needs. The clinical team included the first and third author, who saw five clients between them $(22.7 \%)$.

All 22 participants took part in interviews after the fourth session psychotherapy session (post-session 4 interview). However, the seven participants who had an unplanned ending did not take part in follow up interviews, which took place within one month of the end of therapy. This left 15 participants at follow-up: 11 females $(73.3 \%)$ and four males $(26.7 \%)$, with an average age of 25.7 years old $(S D=9.7)$, and a mean PHQ-9 score at assessment of $18.3(\mathrm{SD}=4.4)$. Of these, one participant's follow-up interview was inaudible 
and therefore not included in the analysis. This gave follow-up interview data on 14 participants, $63.6 \%$ of the total sample.

Of the 22 participants, all but one chose to set goals using the Goals Form (Cooper, 2015, see below), with an average of 3.8 goals per participant (range: 1 to 6 goals). Example goals were, "Manage stress and anxiety" (Client 8), and "To understand why I get to a place of excessive doing" (Client 13).

\section{Procedure}

\section{Pluralistic therapy for depression.}

Pluralistic therapy for depression (PfD) is a manualized, collaborative-integrative psychotherapy (Cooper \& McLeod, 2011; McLeod \& Cooper, 2012). It consists of one 90minute assessment session followed by up to 24 sessions of one-to-one therapy. In PfD, the therapist draws on a range of established treatment methods (e.g., Rogerian active listening, Socratic dialogue, exploration of early childhood experiences) with the aim of tailoring the intervention to the specific goals and preferences of the client (Cooper \& McLeod, 2011). The approach is structured around metatherapeutic communication (Papayianni \& Cooper, 2017): moments of shared decision-making in which therapist and client agree on the particular tasks, goals, and methods of the work.

Pluralistic therapy for depression is supported by the use of the Goals Form (Cooper, 2015). This is a simple idiographic instrument, designed for use in routine outcome monitoring. The form invites clients to state up to five, personalized goals for treatment, and then to rate these goals, at each session, on a 1 (not at all achieved) to 7 (completely achieved) Likert-type scale. Following goal discussion, a digitized version of this form was completed at initial assessment, with clients re-rating their goals at the start of each subsequent session. Clients were informed that they could delete, add, or modify their goals; 
and, in these cases, the Goals Form was modified accordingly. Psychotherapists were also instructed to formally review the client's treatment goals at session four and ten.

\section{Interview schedule.}

Our principal source of data was post-session 4 interviews, conducted an hour prior to clients' fifth psychotherapy session. These were scheduled for up to 60 minutes. We focused interviews at this time point as it was close to the initial assessment session, where PfD particularly encourages goal work to take place (in the form of goal setting), but it also allowed time for goal dialogue and goal tracking to be experienced.

Thirteen of the post-session 4 interviews were conducted by either the first or third author (never their own clients), and nine interviews were conducted by an independent researcher. The interviews were based on a flexible interview schedule, with a set of standard questions and follow-up probes aimed at empathically exploring clients' experiences of working with goals. The interview questions were designed to understand how clients had experienced goal discussion, goal setting, and goal tracking through the use of the Goals Form, as well as broader goal discussion across the course of the treatment. We focused on both positive and negative aspects of goal-oriented practices. A key question, for instance, was, "Was being asked about your goals a helpful or unhelpful part of the therapeutic process?" with the follow-up prompt "If so, how?"

Follow-up interviews were also conducted with participants, within one month of ending therapy. These were carried out for validation purposes, and to identify clients' emerging perspectives on goal-oriented practices (e.g., Elliott, Fischer, \& Rennie, 1999). These interviews lasted for approximately 45 minutes and were primarily unstructured, with questions about goal-oriented practices embedded within a broader debriefing schedule. At the start of these interviews, clients were encouraged to reflect on any changes that came about during therapy and their experiences of goal-oriented practices. Interviews contained 
such prompts as, “Can you say more about your experience of working with goals?” and "Would you choose to work with goals in therapy again?" Where clients readily talked about their experiences of goal-oriented practices, further prompts were used to empathically explore these accounts.

\section{Analysis}

\section{Post-session 4 interviews.}

The post-session 4 dataset was analyzed following Braun and Clark's (2006) thematic analysis. The analysis process comprised a series of phases. First, the interviews were transcribed and then read through several times for the purpose of familiarization. Notes were kept in a reflexive journal for emerging ideas and thoughts, and to bracket personal experience from the data (Hill et al., 2005). In a second phase, initial codes were generated, reflecting basic patterns of meaning identified in the text. A third phase consisted of organizing the codes into broader themes and subthemes, under three overarching domains:

(a) Helpful aspects of goal-oriented practice; (b) Challenging aspects of goal-oriented practice; and (c) Aspects of goal-oriented practices that could facilitate experiences of relevance, investment, and progress. At this point, themes and subthemes were named and defined in a codebook. All the collated coded extracts in each theme and subtheme were reread to consider whether they fitted the theme/subtheme and formed coherent units. Extracts were reshuffled and the structure was changed, where necessary. Finally, the themes and subthemes were written up in narrative format.

Saturation - meaning that the inclusion of new cases did not lead to any substantial revision of the already developed themes - was reached at 17 interviews. However, we included five further confirmatory interviews: where conceptual categories have been determined prior to analyzing the text (e.g., Krippendorff, 2004). To aid clarity of reporting, 
we describe frequency of responses in the narrative using Rodgers and Cooper's (2006) scoring scheme for qualitative thematic analysis: $A l l=22$ cases, $n e a r l y$ all $=20-21$ cases, most $=13-19$ cases, around half $=11-12$ cases, some $=3-10$ cases, a couple $=$ two cases, and one $=$ one case. We followed Hill et al.'s (2005) variance categorization, which suggests that analyses retain categories with at least four cases when a dataset is larger than 15 . Transcript line numbers ("l..”) are given with direct quotes.

Analysis and write-up was primarily conducted by the first author. However, all three authors conducted an analysis of the first two transcripts to establish internal agreement on suitable codes, themes, and subthemes. Following data saturation, the second author audited the codebook and data; and a focus group was held between all three authors to agree on themes and subthemes. At the write-up stage, themes and subthemes were again reviewed and revised by the second and third authors.

\section{Analysis of follow-up interviews.}

The first author listened to all 15 interviews, and noted down extracts that contained content about goal-oriented practices. These extracts were then transcribed and analyzed, using the themes and subthemes developed in the post-session 4 analysis as sensitizing concepts (Blumer, 1954). This means that the previous themes and subthemes guided the analysis — not as definite concepts with clear criteria for inclusion and exclusion- but as categories that alerted the research team to similar patterns, and which could be modified by new findings. For this analysis, we again followed Hill et al.'s (2005) variance categorization, which suggests that analyses retain categories with at least two cases when the dataset is smaller than 15. As not all interview data were transcribed, direct quotes here are referenced with a time stamp.

\section{Integration of findings in relation to a directional framework.}


Following the analysis of post-session 4 and follow-up interviews, the order of themes and subthemes were reorganized in the light of Cooper (2019)'s directional arc. Core themes were also developed for each domain, which reflected premises and phases of this broader theoretical framework.

\section{Correlates of goal attitudes.}

To explore possible factors that might predict whether participants were more, or less, positive towards goal-oriented practices, we created a "goal attitude" score for each participant. This consisted of the number of "helpful" themes (Domain 1) within which the participant's interview(s) had been coded (either at post-session 4 or at follow-up), minus the number of "challenging" themes (Domain 2) within which it had been coded. As we had six helpful themes and seven challenging themes (see Table 1), the theoretical range of this goal attitude score was from -7 to +6 , with higher scores indicating more positive attitudes towards goal-oriented practices. To avoid over-specification, we focused only at the theme, rather than subtheme, level; and did not count specific numbers of text units coded at each theme. We then conducted correlational tests (Spearman's rank-order correlation, $r_{s}$ ) to explore whether goal attitudes were associated with participants' age, baseline levels of depression and anxiety, and gender. We also explored correlations between goal attitude scores and changes in depression (PHQ-9) and anxiety (GAD-7), both with and without controlling for baseline scores using regression analysis (goal attitude as dependent variable, then entering baseline scores, then entering change scores). Analyses were conducted using IBM SPSS Statistics 25 and, as exploratory analyses, we used a $p$-value of .05 without adjustment for multiple testing. 


\section{Results}

Domains, themes, and subthemes for the post-session 4 analysis are presented in Table 1. Of the 22 participants, $19(86.4 \%)$ identified both helpful (Domain 1) and unhelpful (Domain 2) elements of goal-oriented practices.

\section{Domain 1. Helpful Aspects of Goal-Oriented Practices \\ Core theme: Helped clients move from intention to action.}

A phenomenon that integrated all findings within this domain was that goal-oriented practices helped clients become aware of - and focused on — themselves, what they wanted, and what they could do: all of which helped them take the next steps in a "wished-for" direction. The clients highlighted how these aspects of the practice increased their sense of achievement, and motivated action.

Goal-oriented practices facilitated introspection and a greater awareness of oneself and problems. Most clients reported feeling more aware, and thinking about themselves and their problems more, as a result of goal-oriented practices. Some clients felt working with goals provided a greater awareness of behaviors, plans, and steps to achieve their goals. For instance, "Now I'm like 'no' because my goal is to not do that, (...) this has made me a lot more aware" (Client 6, 1. 202). Likewise, some stated that goal-oriented practices were linked to a greater awareness of their thoughts and feelings. Some clients stated that goaloriented practices invited them to be more consistently aware of what they were striving for. Here, some clients specifically referred to "keeping goals in mind" more, such as: "I actually had them in my head, which is really weird. So, when I'd go home I'd have them in my mind" (Client 17, 1. 57).

\section{Having goals brought clarity, associated with a problem being easier to solve or}

share. Related to awareness and introspection, around half of the clients felt that having goals gave them more clarity around understanding their problem. Some clients suggested that 
having goals that were concrete or "in words" simplified or clarified their problems and made them easier to solve. Similarly, participants described greater clarity through the process of writing goals down on paper. For instance, Client 12 said: "Even though I knew they were the things I wanted, it was all jumbled up in my head so to actually write it down on paper...made it a bit easier or it just clarified it a little" (1.37). For some clients, this increased clarity was associated with the value of understanding and sharing their goals.

Goals brought a focus that enhanced motivation, created a common ground, and was enabling of action and expression. Most clients reported that having goals was helpful in that it gave them a sense of focus that facilitated processes associated with goal progress. Around half described a focus and direction associated with the motivation to progress towards goals, for instance: "I think it's good 'cause it gives me something to really work towards" (Client 6, 1. 65). Some clients experienced the goals focus as a form of "common ground" where goals would be used as a point of reference in the therapeutic dialogue. Some clients found that the goals focus was "enabling": for instance, allowing them to express "what I want and what I need" (Client 3, 1. 329). Some clients also felt that it enabled them to act and change, Client 16 stated: "When I had that goal in place it forced me to think past, 'I don't know'. So, that meant we could sort of get somewhere” (1. 31).

\section{Having goals contributed to a predictable structure that felt safe and comforting.}

Some clients reported that goal-oriented practices could contribute to a safe, comforting structure, enhanced by the predictability and consistency of the goals work. Client 11 said, "I quite like knowing what I'm in for so I like to come in and know that I'm sitting here or that's how we're going to start a session" (1.240).

Goal-oriented practices implied breaking down superordinate goals into manageable tasks that relieved pressure or facilitated a sense of achievement. Around half of the clients described the use of subgoals as a helpful aspect of goal-oriented practice. This 
was the process of breaking down difficult—but important — superordinate goals into more manageable tasks. Some clients experienced the use of subgoals as bringing a sense of relief from pressure. For instance, Client 3 stated: "Usually I put loads of pressure on myself to just go straight for the big goal...I think she helped me take baby steps, rather than...get completely overwhelmed, which is what usually happens" (1. 116).

Some clients said that these subgoals were more attainable, and therefore more likely to give a positive sense of progress and achievement. Client 18 stated, "I haven't achieved getting a job, yet, but I've achieved the smaller goals, which makes me feel better' (1. 100).

\section{Goal-oriented practices implied monitoring goal progress that guided and}

reinforced client progress. Some clients stated that tracking goal progress was helpful. Some clients said that this was because monitoring helped them see results, which then guided and supported their progress. For instance, Client 3 said: "It's always nice to see that I've made progress. But, having it on paper or having someone else say it, is like... it being reinforced that I am making progress" (1. 133).

\section{Domain 2. Challenging Aspects of Goal-Oriented Practices}

\section{Core theme: Hindered awareness and clarity of own intentions and potential} steps forward.

Aspects of goal-oriented practices that clients experienced as difficult or unhelpful revolved around feelings of irrelevance and not being poignantly understood, either with regard to themselves as persons, the nature of their problems or wants, or the particular circumstances and point in time.

\section{Creating goals felt demotivating and pointless due to the overbearing nature of} clients' problems. Some clients had felt demotivated or unable to set, or break down, goals. For some clients, this was due to identifying with their problems, for instance, Client 1 stated: 
"it's difficult to think about it [the problem] because it's a part of me, it's a part of what I do, so it's difficult to put into words" (1. 141). Similarly, some clients were demotivated to work with goals (and, particularly, subgoals) because they identified with, or felt strongly about staying with, the "big picture". Others were demotivated as the amount of hurdles to overcome felt overwhelming.

Formulating goals was difficult due to uncertainty in the beginning of therapy. Most clients experienced some uncertainty at the start of therapy, which led to doubts and difficulties associated with goal-oriented practices. Around half of the clients experienced uncertainty around their expectations of therapy processes, which could be disorientating and impact on goal setting. For instance, "It's nice that I was asked my opinion on something...but it kind of put me in the spotlight a bit and I was just there, like...'I don't know, whatever you think is best"” (Client 3, 1. 60).

Some clients stated directly that they experienced uncertainty around identifying their goals at the start of therapy. They found it difficult to make seemingly very important decisions in a short space of time, and with little insight. Client 5 stated: "I was, like, talking about all these goals and I was like 'I don't really know what I want—-that's part of the reason why I'm here' so... yeah, that was kind of difficult" (1. 19). For some clients, this uncertainty over goal setting was associated with a lack of self-understanding and insight.

Articulating problems in terms of goals could feel incongruent with a client's lived experience. Some clients experienced goal formulations as incongruent with their experience and understanding of issues. For instance, some felt their problems were too broad to be formulated as goals. Client 5 stated, "it's like- the three main big issues of my life put down on a bit of paper... I think they are too broad to be put down in that way" (1. 377). Others felt that goals did not represent the way that they perceived or experienced the world. 


\section{Clients would not feel heard because of a mechanistic structure or}

misrepresentation of their problems. Some clients stated that goal-oriented practices could lead them to feel misheard. For some, this was because goal-oriented practices might downplay the seriousness of their problems. A few clients specifically said that goal-oriented practices were unhelpful because they felt mechanistic. Client 5 said, "To talk about it in this way all the time, sometimes it can be hindering...it's almost like a checklist. It's almost, like, if it's something so easy to just, cross it off' (1. 191).

Setting goals involved commitment that increased fear of failure. Some clients felt stuck in creating goals, because turning an important problem into a goal raised the possibility of failing to overcome or achieve it. Client 9 stated, "I probably feel more of a sense of a failure if I were to decide, 'I really want to work on this or aim for this,' and then that not be the end result. So, I'd rather leave it open-ended" (1. 50).

Goals could become irrelevant over time. Some clients said that their goals had become irrelevant because of a change in priority due to circumstances, knowing or understanding something new; or because of having achieved, or come to terms with, their goals. Client 8 stated, “And now when I come to them [the goals] each week, I'm just a bit like, 'Um, does it matter?’” (1. 215). For some clients, the goals had become irrelevant because they addressed issues at the time they were created or, in fact, they had been originally formulated to please the therapist.

\section{Shifting affects associated with changing perceptions of progress could be}

disorientating. Some clients felt the lack of achievement or progress towards a goal could leave them feeling down: "If my sleep has really gotten me down all week, sometimes doing the goals is harder, because it's so exasperating to look at your goals and go, 'I'm still in the same place I was"' (Client 8, 1. 115). For some clients, oscillating affects could be disorientating, and tiring: "if I manage it one day then I will feel really good about myself 
that one day but I will feel pretty shit the next day when I fail.... And that's exhausting in the long run" (Client 1, 1. 162).

\section{Domain 3: Aspects of Goal-Oriented Practice that could Facilitate Experiences of}

\section{Relevance, Investment, and Progress}

Core theme: The relevance and effectiveness of goal-oriented practices hinged on client, therapist, and treatment factors.

Clients' reports of facilitating factors pointed to clients' management of their own expectations; therapists' supportive, targeted interventions; and an atmosphere of collaboration, flexible structure, and sufficient time.

Clients emphasized how they managed their own expectations around goal-oriented practices. Most clients reported on their attempts to proactively manage their own expectations in facilitating goal-oriented work. Some clients said that it was helpful when they were realistic about their goals and tried to ensure that they were achievable, and some felt it was helpful to be realistic about the time it could take to achieve their goals. For instance, Client 13 said, "It's not going to happen in just a few months because these are too big things. So yeah, I don't expect to fix this in a few weeks" (1. 88).

Similarly, some clients described accepting the possibility of failing at goals, recognizing failures as part of the process; and some clients also suggested a strategy of setting "low expectations" in order to not be disappointed. Client 9 stated, "I prefer to not put too much hope into things and then be mildly surprised when good things come of it, rather than going with expectations and being disappointed" (1. 54). Some clients, on the other hand, felt that it was helpful to have more flexible expectations. For example, Client 13 stated, "I try them out, see if they work within specific situations, it might work, it might not" (1. 113). 


\section{Clients experienced goal-oriented practices as enhanced when therapists offered}

targeted, supportive interventions. Most clients reported that goal-oriented practices had been enhanced through therapist supportive interventions. Around half of clients experienced their therapists as facilitating goal-oriented practices through listening and allowing a space for reflection. Some clients also experienced therapist support and reassurance around goaloriented practices as confidence-giving or facilitative.

Around half of the clients felt it was helpful to be guided by the therapist in goaloriented practices. Client 2 stated, "She's kind of helping pick out a book on a book shelf essentially, and which one and where it is" (1.29). Some, on the other hand, experienced therapists taking the lead or giving advice as facilitative. For instance, Client 6 said: "If I get distracted or talk about something else, she tells me, 'No, this is not what you're here to be talking about' kind of thing." (1. 167).

Some clients talked about therapists facilitating goal-oriented practices through pointing out what could be helpful in this work or engaging in helpful goal-related therapeutic tasks. This was, for instance, through creating links between goals, and through supporting progress monitoring, for instance with the therapist noticing client progress. It could also be through encouraging clients to be more specific.

The benefits hinged on a flexible structure around goal-oriented practices. Most clients found having a flexible structure around goal-oriented practices enhanced their value. Around half found that a flexible structure could best orient the therapy process and help make more organic decisions about what was most relevant. Client 2 said: "We were going to talk about motivation originally...then I said, 'actually, this is a concern at the moment...this has happened', and that's how we, kind of, came about it" (1. 215). 
Furthermore, some clients suggested that a flexible structure would help to address, and reflect, their unique preferences regarding goal setting. This might be to set goals collaboratively or in a more client-directed way.

Some clients suggested that a flexible structure in the psychotherapy might allow for meanings around the goals to emerge more fully. This could be linked to more depth in therapy, for instance, Client 2 said: "If I don't feel like talking about those [goals] ...we could talk about something else, which...still has an impact. I really enjoy that philosophical, hypothetical debate about 'am I a bear'...it's deeper, it's more profound” (1. 200). Similarly, a flexible structure was associated with more flow and trust.

Some clients suggested that goals could be as helpful when they were implicit in the work, as when they were made explicit. Client 1 said, "I think whether they were there or not as goals wouldn't matter because they're there in another presence if they matter" (1. 11).

\section{Helpful goal-oriented practice was facilitated by having enough time in sessions}

and for the therapy. For around half the clients, feeling they had enough time in therapy, and in sessions, facilitated goal-oriented practice. Some clients suggested that time would enable them to experience and know what they truly wanted from therapy. For Client 13, this was associated with developing trust in oneself, 'So maybe that's why it [the goal] didn't come up at first because it's something that I maybe consciously wasn't yet ready to be working on' (1. 209). Alongside this, some clients said that having enough time could help getting to know and establish trust with their therapist, which could then deepen the value of goal-oriented practices.

Some clients felt having enough time was helpful in order to go into specifics around goals. Similarly, some clients said that having enough time generated greater hope in achieving their goals. 
Clients experienced processes of dialogue and collaboration as facilitative in goaloriented practices. Some clients described a process of dialogue, response to feedback, and collaboration in goals discussions as facilitative of goal-oriented work. For instance, Client 2 said, "We have critical discussions about stuff and I will say what I need to say and she will say what she needs to say, and I will accept what she says, whether or not I fully agree with it I will let her know or I will fully agree with her or not" (1.274).

\section{Follow-up Interview Analysis}

All post-session 4 themes were populated by data from at least two cases at follow-up (Table 1), except for two themes: Having goals contributed to a predictable structure that felt safe and comforting (Domain 1), and Helpful goal-oriented practice was facilitated by having enough time in sessions and for the therapy (Domain 3).

Four new themes were identified at follow-up interview. The first of these sat broadly within Domain 2, and the remaining three within Domain 3.

Not setting goals could have helped focus on more implicit directions, reduce expectations, and limit a sense of failure.

Three clients - including the one client who did not set goals from the start of therapy (Client 9) — stated that it might be most helpful not to have goals in therapy. This was because not having goals was seen as helping to focus on more implicit, unconscious desires. Furthermore, it was suggested that less expectations might lead to "pleasant surprises", and might also limit a sense of failure when goals were not achieved. These clients also said that not having goals could feel more "gentle" to some clients.

\section{Goal-oriented practices require a client's readiness to engage with this process.}

Five clients indicated a need to be ready in order to set goals and engage in goaloriented practices. For instance, Client 21 said, "When I first came in, goals were too 
distant for me. To have goals you have to be sure-footed, you have to have your feet anchored...that's what I initially needed to secure the things that I wanted" (00:23:40). Readiness was also associated with a client's need for self-understanding and awareness prior to setting and attempting to reach goals.

\section{Negotiating balance between acceptance and progress with regards to goals.}

Four participants reflected on a new understanding of wanting to progress towards their goals but also finding a sense of acceptance around not achieving their goals fully. For instance, Client 2 stated, "I feel like I'll never completely achieve them, but I feel like they're as achieved as they'll become, they're level six [out of seven on the Goals Form] rather than a seven" (00:45:07).

\section{Monitoring goals too often was not helpful due to the lack of time to make} enough progress or any progress.

Three clients reported that weekly monitoring of goals was not helpful, as it did not leave enough time for clients to make progress. Client 5 said: "Once in a while, that's fine, but every week, it wasn't helpful" (00:34:10). Therapist asking about the lack of progress was described as being particularly unhelpful.

\section{Correlates of Goal Attitudes}

On average, clients were coded within 3.5 helpful themes $($ Median $=3.5$, Mode $=3$, $\mathrm{SD}=1.7$, range $=0-6)$, and 3.1 challenging themes $($ Median $=3$, Mode $=3, \mathrm{SD}=1.6$, range $=0-6)$. This gave a mean goal attitude score of $0.5(S D=2.1$, range $=-3-5)$.

Male and female clients did not differ significantly in how positive they were to goaloriented practices, nor was there a significant correlation between age and goal attitudes. However, we found a large negative correlation between goal attitude and baseline depression score $\left(r_{s}=-.51, p=.015\right)$, as well as with baseline anxiety score $\left(r_{s}=-.60, p\right.$ 
$=.004)$. This indicated that participants who were more symptomatic at assessment described more challenging, and less helpful, aspects of goal-oriented practices.

A large positive correlation was found between goal attitude and reductions in depression symptoms $(r=.49, p=.021)$, as well as with reductions in anxiety symptoms $(r$ $=.50, p=.017)$. These relationships remained significant when we controlled for baseline levels of depression and anxiety, respectively. Post hoc categorical analysis showed that, of the eight clients whose interviews were coded under more "challenging" than "helpful" themes, the mean improvement on the PHQ-9 was 0.8 points, with one client $(12.5 \%)$ showing reliable improvement. By contrast, of the 11 clients whose interviews were coded under more "helpful" themes than "challenging" ones, the mean improvement on the PHQ-9 was 8.5 points, with nine showing reliable improvement on the measure $(81.8 \%)$. Hedges' $g$ for the mean differences between these two groups was 1.6, with an odds ratio of 31.5. For reductions in anxiety symptoms, the Hedges' $g$ between these two groups was 1.3 , with an odds ratio of 18.7 .

\section{Discussion}

To our knowledge, our study is the first empirical examination of whether the benefits of goal-oriented practices, as identified in psychological research (e.g., Locke et al., 1981), extend in to the psychotherapeutic domain. Here, we found evidence that goal setting and goal monitoring, within a psychotherapeutic context, can help clients focus their efforts (Michalak \& Grosse Holtfort, 2006). Similarly, our findings suggest that the motivating and mobilizing effects of goal setting and goal monitoring can translate to the psychotherapeutic domain. We also found support for the hypothesis that goal-oriented practices can help clients establish more realistic treatment expectations (Smith, 1994), with clients highlighting their value in breaking down superordinate goals into more manageable tasks. However, while Smith (1994) hypothesized that goal-oriented practices foster therapist-client 
collaboration per se, our findings suggest that additional benefit rather seems to come from enhancing clients' awareness of, and clarity about, their problems. This latter finding may not have emerged in previous psychological research because, within that context, goals are often set for participants, and the development of insight is not a salient or valued process, perse.

Despite these potential benefits, we also found clear evidence that goal-oriented practices could be experienced as having unwanted or negative effects. Consistent with previous hypothesizing (Cooper \& Law, 2018) we found that, at the start of therapy, many clients felt that they did not know what their goals were. Here, goal-oriented practices were not necessarily experienced as unhelpful; but could lead to feelings of disorientation, discomfort, or awkwardness, as clients "scrabbled around" to identify goals. We also found a small minority of clients saying that the explicit setting of goals may have interfered with the identification of more implicit, unconscious directions. Furthermore, in partial support of the humanistic critique (Rowan, 2008), we found a few clients who experienced goal-oriented practices as mechanistic, or as inconsistent with their lived-experiences. Additional limitations of goal-oriented practices, not previously identified in the literature, were that they could increase clients' fears of failure, as well as actual feelings of failure if they were making "poor" goal progress.

Our findings provide empirical support for previous guidance in the psychotherapy field: that goal-oriented practices should be carried out in collaborative and flexible ways, across the course of the psychotherapy treatment (e.g., Feltham et al., 2018; Michalak \& Grosse Holtfort, 2006). Again, they also provide the first empirical support for the claim that, for clients, the setting of "small steps" may be experienced as particularly helpful. A novel finding, however, was that clients saw psychotherapists as having an important role in facilitating effective goal-oriented practices: listening, leading, and emphasizing the helpful 
aspects of this work. In addition, our participants recognized the role that they, as clients, had in managing their own goal expectations. This is consistent with understandings of the client as an active agent in the change process (e.g., Bohart \& Wade, 2013). A third novel finding in this domain was that, for around half of the clients, it was important to have enough time to engage in goal-oriented practices.

Our finding that all but two of the themes in these domains were replicated at two separate interview points, approximately 4-5 months apart, suggests that these findings are consistent over time. In addition, new themes emerging at the end of therapy may reflect novel perspectives on goal-oriented practices, acquired during the therapy process. One novel perspective was clients' reports that goal-oriented practices relied on their readiness to engage with the therapeutic process. This perspective is in line with numerous findings demonstrating the impact of clients' motivation and readiness for change on process and outcome (e.g., Bohart \& Wade, 2013). Another finding that emerged at follow-up was clients' reports on the effects of routine goals monitoring. Although, at both post-session 4 and follow-up, several clients indicated that goal tracking guided and reinforced progress, by endpoint there were three clients who felt weekly monitoring was not helpful. At follow-up interview, around a third of the clients had also come to feel that it was important to accept the impossibility of ever fully achieving certain goals. In these respects, over the course of their therapy, some clients seemed to develop more sophisticated, nuanced, and complex understandings of goal-directed processes. That is, that achieving their goals was not an immediate, all-or-nothing process; but one that took time and effort, with progress more important than achieving a definitive endpoint.

We were surprised by the large associations between attitudes towards goal-oriented practices and outcomes, with clients who were "positive" towards this work 20 to 30 times more likely to reliably improve compared with clients who were "negative". This association 
may have simply come about because clients who were making more progress in the work found — or were motivated to describe — its components as more helpful. It may also reflect some "third factor", such as a willingness to engage with psychotherapy, which could have led to both improved outcomes (Bohart \& Wade, 2013) and a greater gusto when describing the components of the work. Due to our design and sample size we cannot rule out the possibility that differences in therapists' effectiveness might have influenced this association too. However, there is also the possibility that clients who were more open and willing to engage in goal-oriented practices were better able to make use of psychotherapy, and this is an important area for further research. At the very least, what our finding suggests is that a negative attitude towards goal-oriented practices may be a marker of poorer therapeutic prognosis, and is something that therapists should be alert to.

Our finding that more symptomatic clients were more negative towards goal-oriented practices is also an intriguing one. Again, this may simply reflect a broader attitudinal stance: these clients may have felt more negative, hopeless, and demotivated in general. However, other possibilities are that highly symptomatic clients were less able to make use of goals; felt less confident in achieving them; or were, perhaps, so focused on their immediate concerns that medium to longer term objectives seemed irrelevant. These findings need further investigation but suggest that, potentially, therapists should be more cautious in adopting goal-oriented practices with more distressed clients. Or, if these practices are adopted, it may be particularly important to explain their rationale for use.

\section{Theoretical Integration of Findings}

Our results lend some support to Cooper's (2019) theoretical framing of goal-oriented practices within a directional arc, but add some important nuances. Participants' reports that goal setting could create foci to enable, motivate, and maintain actions supports the hypothesis that goal-oriented practices may be particularly facilitative during the action 
phase. Goal setting also seemed to be helpful in the action and planning phases by allowing superordinate goals to be broken down into more manageable tasks. However, our results suggests that goal setting also has the capacity to be helpful in earlier phases-awareness and evaluation - by helping clients to gain a greater insight into their higher-order wants and desires.

The doubts and uncertainties that many clients experienced in setting goals at the start of psychotherapy is also consistent with Cooper's (2019) framework, suggesting that clients may find goal-oriented practices less helpful at the "pre-intentional" phases of the directional arc. Here, where clients were not clear about what they wanted, goal-oriented practices could be experienced as irrelevant; rushed; or distracting from deeper, more implicit desires. Consistent with this, many clients indicated that they needed "time" to be able to use goaloriented practices productively, that it required dialogue and collaboration with their psychotherapists, and that they needed to be ready to engage with goal-oriented processes. Given that negative attitudes towards goal-oriented practices may reflect an underlying unreadiness here, this may explain why clients with a predominance of such views had much poorer outcomes. This is consistent with the premises of transtheoretical phase models, which hold that different types of change processes are involved at different phases of therapy (e.g., Grawe, 1997, 2004; Howard, Lueger, Maling, \& Martinovich, 1993; Krebs, Norcross, Nicholson, \& Prochaska, 2018; Miller \& Rose, 2009). For example, within the "stages of change" model insight or awareness oriented processes are associated with progress in stages of "pre-contemplation" and "contemplation" (Krebs et al., 2018): similar to the emergence and awareness phases of the directional arc. Thus, spending enough time, and ensuring that the goals are fit with how clients understand themselves and their situation, may be particularly important in these early phases. 
As proposed by Cooper (2019), our results suggest that goal-oriented practices could also support progress in the feedback phase of the directional arc, through goal monitoring. However, while previous studies suggest that goal monitoring facilitates goal actualization through enhancing self-regulatory processes (Harkin et al., 2016), we found that goal monitoring was primarily beneficial through reinforcing clients' feelings that they were making progress. The "shadow side" of this process, however, was that clients could also feel demotivated if they saw themselves failing to progress, or disoriented if their progress was mixed; and by the end of therapy a few clients felt that weekly goal monitoring was "too much". These findings may be of particular importance given that positive affect, and particularly feelings of self-efficacy, can stimulate goal-directed efforts; while negative affects, and low self-efficacy, can have the opposite effects (e.g., Azjen, 1991; Gollwitzer et al., 2012). Hence, goal monitoring may have the potential to catalyze both virtuous and vicious cycles: clients progressing further because they feel that they are progressing well, or prematurely giving up on goals because of a lack of explicit goal progress.

What was also apparent in our findings, as discussed by motivational theorists such as Cooper (2019), Powers (1973), and Grawe (2004), is that clients' feelings about their goals was as much to do with their expectations (or "reference conditions", Power, 1973), as with their actual levels of progress. Indeed, for some clients, simply setting up goals created expectations that were unhelpfully threatening. Here, most clients recognized that they needed to manage their own goal expectations: setting, for instance, "baby steps" that could alleviate feelings of pressure, and finding a balance between ambition and acceptance of "failure".

\section{Study Limitations}

There are a number of important limitations to this study. First, data at follow-up was not as rich as our post-session 4 data, as it came from a more generic debriefing interview. 
Our new findings at this interview point, therefore, should be considered tendencies that need further investigation. Second, as the study was dependent on participants' subjective perceptions, the actual aspects of goal-oriented work that are helpful and unhelpful to psychotherapy outcomes - and the factors that enhance its value - may be different from those reported. Another limitation is that two of the authors were involved in the treatment and the interviews (although not with their own patients), and determined and organized the qualitative themes. This means that reification might have occurred. However, one of the authors was entirely independent to the treatment and interviewing process. Generalizability is also limited by the lack of ethnic diversity, and the fact that we only interviewed approximately three-quarters of those attending psychotherapy during our designated time period (and a smaller proportion during follow-up). Our research also focused on goaloriented practices as a constellated set of activities, rather than focusing on specific elements, such as goal setting or goal tracking, in isolation.

The conducting of this research with a specific population may also have implications for generalizability. For instance, clients meeting criteria for depression may find it more difficult to identify goals, or experience greater demotivation when failing to achieve them, as compared with other client groups. Equally, the context for this research-a collaborative integrative psychotherapy, in which goals were explicitly set and monitored through the Goals Form - limits the generalizability of the findings. Having said that, the themes and subthemes that emerged appear relatively applicable to different psychotherapeutic approaches, and not specific to collaborative-integrative psychotherapy. It seems reasonable to hypothesize, for instance, that clients in CBT may also experience goal-setting as enhancing motivation, or find goals difficult to formulate at the start of therapy. 


\section{Implications for Practice}

The findings from this study have several important implications for goal-oriented practices in psychotherapy: providing empirical backing for previous recommendations, and generating new ones. First, and most generally, they suggest that goal-oriented practices have the potential to be both beneficial, and unhelpful, to clients. Hence, therapists should determine with clients, on a case-by-case basis, whether and how goal-oriented practices should be incorporated into the work. Findings from Domain 1 suggest that goal-oriented practices may be particularly helpful in the planning, action, and feedback phases of the directional arc: when there is a need to enhance focus, motivation, structure, and awareness; or where clients are overwhelmed with problems and might benefit from having them broken down into manageable tasks. Concomitantly, goal-oriented practices may be least helpful where clients are in the emergence and evaluation phases and do not know what their goals are: or where they do not see the world - or do not want to see the world —in "goal-oriented" terms, and where they are sensitive to failures in goal attainment.

Where goal-oriented practices are adopted, findings from this study also suggest a number of practice considerations. First, therapists should consider allowing clients sufficient time to explore and set their goals. This may mean that-provided the treatment is mid to long term - treatment goal setting should be extended into a second or third session, or even longer, rather than at an initial meeting. If goal-oriented practices are adopted, a second implication is that this work should be conducted collaboratively and flexibly. Here, therapists should actively invite clients to share their views, but also input their own ideas and expertise into the goal setting process. In addition, therapists should be willing to let goals "go" and change track if other issues become more salient. Third, the most helpful goal setting strategy may be one in which therapist and client establish relatively small, achievable subgoals. Fourth, closely related to this, goals should be regularly reviewed; with new goals 
established when previous ones have been achieved, or are no longer relevant. Fifth, goal tracking seems generally to be a helpful process, but therapists should also be aware of its potential to demoralize clients where they are not showing "good" progress. Therapists, therefore, should act sensitively in such situations: for instance, reminding clients of progress they are making in other areas of their lives. Finally, therapists should consider means in which they might provide supportive interventions regarding treatment goals. For instance, clients might be provided with pre-treatment information encouraging them to think about what they would like from the therapeutic process, and what they would consider achievable within the time available.

\section{Implications for Further Research}

For future research, it would be helpful to focus down on clients' experiences of specific goal-oriented practices, such as goal setting in an initial therapy session, or goal tracking at the start of each session. As part of this, it would also be very helpful to consider clients' experiences of using particular goal-based tools, such as Goal Attainment Scaling (Kiresuk \& Sherman, 1968). Controlled studies on the effects of goal-oriented practices are also required, to identify the outcomes of particular methods and instruments (see, for instance, Sheldon, Kasser, Smith, \& Share, 2002). Further research should also examine the various manifestations of helpful and unhelpful goal-oriented practices related to particular contexts, client groups, and phases of the directional arc. Finally, we recommend building on theoretical frameworks, such as Cooper's (2019) directional arc, to develop more integrated, coherent, and in depth accounts of the uses and misuses of goal-oriented practices in psychotherapy.

\section{References}

Bargh, J. A., Gollwitzer, P. M., Lee-Chai, A., Barndollar, K., \& Trötschel, R. (2001). The automated will: Nonconscious activation and pursuit of behavioral goals. Journal of 
Personality and Social Psychology, 81(6), 1014-1027. doi: 10.1037/00223514.81.6.1014

Blumer, H. (1954). What is wrong with social theory? American Sociological Review, 19, 310. doi: $10.2307 / 2088165$

Bohart, A. C., \& Wade, A. G. (2013). The client in psychotherapy. In M. J. Lambert (Ed.), Bergin and Garfield's handbook of psychotherapy and behavior change (6th ed., pp. 219-257). Chicago: John Wiley and Sons.

Bordin, E. S. (1979). The generalizability of the psychoanalytic concept of the working alliance. Psychotherapy: Theory, Research \& Practice, 16(3), 252-260. doi: $10.1037 / \mathrm{h} 0085885$

Braun, V., \& Clarke, V. (2006). Using thematic analysis in psychology. Qualitative Research in Psychology, 3(2), 77-101. doi: 10.1191/1478088706qp063oa

Cooper, M. (2015). The Goals Form. University of Roehampton. London. Retrieved from https://www.researchgate.net/publication/286928866_Goals_Form

Cooper, M. (2018). The psychology of goals: A practice-friendly review. In M. Cooper \& D. Law (Eds.), Working with goals in counselling and psychotherapy (pp. 35-71). Oxford: Oxford University.

Cooper, M., Dryden, W., Martin, K., \& Papayianni, F. (2016). Metatherapeutic communication and shared decision-making. In M. Cooper \& W. Dryden (Eds.), Handbook of pluralistic counselling and psychotherapy (pp. 42-54). London: Sage.

Cooper, M., \& Law, D. (2018). Introduction. In M. Cooper \& D. Law (Eds.), Working with goals in counselling and psychotherapy (pp. 1-13). Oxford: Oxford University.

Cooper, M., \& McLeod, J. (2011). Pluralistic counselling and psychotherapy. London: Sage.

Cooper, M., \& Rodgers, B. (2006). Proposed scoring scheme for qualitative thematic analysis. Retrieved from https://strathprints.strath.ac.uk/30517/ 
Cooper, M., Wild, C., van Rijn, B., Ward, T., McLeod, J., Cassar, S., . . Sreenath, S. (2015). Pluralistic therapy for depression: Acceptability, outcomes and helpful aspects in a multisite study. Counselling Psychology Review, 30(1), 6-20. doi: $10.1080 / 13642537.2012 .652395$

Cox, W. M., \& Klinger, E. (2011a). Measuring motivation: The motivational structure questionnaire and personal concerns inventory and their variants. In W. M. Cox \& E. Klinger (Eds.), Handbook of motivational counseling: Goal-based approaches to assessment and intervention with addiction and other problems (2nd ed., pp. 161-204). Chichester: Wiley.

Cox, W. M., \& Klinger, E. (2011b). Systematic motivational counseling: From motivational assessment to motivational change. In W. M. Cox \& E. Klinger (Eds.), Handbook of motivational counseling: Goal-based approaches to assessment and intervention with addiction and other problems (2nd ed., pp. 275-302). Chichester: Wiley.

Creswell, J. W. (2014). Research design. Qualitative, quantitative, \& mixed methods approaches (Fourth edition). Los Angeles: SAGE.

Elliott, R. (2000). The session effectiveness scale. Unpublished questionnaire. University of Toledo. Toledo, $\mathrm{OH}$.

Elliott, R., Fischer, C. T., \& Rennie, D. L. (1999). Evolving guidelines for publication of qualitative research studies in psychology and related fields. British Journal of Clinical Psychology, 38, 215-229. doi: 10.1348/014466599162782

Epton, T., Currie, S., \& Armitage, C. J. (2017). Unique effects of setting goals on behavior change: Systematic review and meta-analysis. Journal of Consulting and Clinical Psychology, 85(12), 1182-1198. doi: 10.1037/ccp0000260 
Feltham, A., Martin, K., Walker, L., \& Harris, L. (2018). Using goals in therapy: the perspective of people with lived experience. In M. Cooper \& D. Law (Eds.), Working with goals in counselling and psychotherapy (pp. 73-85). Oxford: Oxford University.

Fluckiger, C., Del Re, A. C., Wampold, B. E., \& Horvath, A. O. (2018). The alliance in adult psychotherapy: A meta-analytic synthesis. Psychotherapy (Chic), 55(4), 316-340. doi: $10.1037 / \mathrm{pst} 0000172$

Grawe, K. (1997). Research-informed psychotherapy. Psychotherapy Research, 7, 1-19. doi: $\underline{10.1080 / 10503309712331331843}$

Grawe, K. (2004). Psychological therapy. Gottingen, Germany: Hogrefe \& Huber.

Grey, N., Byrne, S., Taylor, T., Shmueli, A., Troupp, C., Stratton, P., . . Cooper, M. (2018). Goal-oriented practice across therapies. In D. Law \& M. Cooper (Eds.), Working with goals in counselling and psychotherapy (pp. 181-203). Oxford: Oxford University.

Grosse Holtforth, M., \& Castonguay, L. G. (2005). Relationship and techniques in cognitivebehavioral therapy--A motivational approach. Psychotherapy: Theory, Research, Practice, Training, 42(4), 443-455. doi: 10.1037/0033-3204.42.4.443

Gyani, A., Shafran, R., Layard, R., \& Clark, D. M. (2013). Enhancing recovery rates: lessons from year one of IAPT. Behaviour Research and Therapy, 51(9), 597-606. doi: 10.1016/j.brat.2013.06.004

Harkin, B., Webb, T. L., Chang, B. P., Prestwich, A., Conner, M., Kellar, I., Sheeran, P. (2016). Does monitoring goal progress promote goal attainment? A meta-analysis of the experimental evidence. Psychological Bulletin, 142(2), 198-229. doi:

\section{$10.1037 / \mathrm{bul} 0000025$}

Heckhausen, H., \& Gollwitzer, P. M. (1987). Thought contents and cognitive functioning in motivational versus volitional states of mind. Motivation and Emotion, 11(2), 101-120. 
Hill, C. E., Knox, S., Thompson, B. J., Williams, E. N., Hess, S. A., \& Ladany, N. (2005). Consensual qualitative research: An update. Journal of Counseling Psychology, 52(2), 196. doi: $\underline{10.1037 / 0022-0167.52 .2 .196}$

Howard, K. I., Lueger, R. J.,, Maling, M. S., \& Martinovich, Z (1993). A Phase model of psychotherapy outcome: causal mediation of change. Journal of Consulting and Clinical Psychology, 61,678-685.

Kiresuk, T. J., \& Sherman, R. E. (1968). Goal attainment scaling: A general method for evaluating comprehensive community mental health programs. Community Mental Health Journal, 4(6), 443-453. doi: 10.1007/bf01530764

Krebs, P., Norcross, J. C., Nicholson, J. M., \& Prochaska, J. O. (2018). Stages of change and psychotherapy outcomes: A review and meta-analysis. Journal of Clinical Psychology, 74(11), 1964-1979. doi: 10.1002/jclp.22683

Krippendorff, K. (2004). Measuring the reliability of qualitative text analysis data. Quality and Quantity, 38 (6), 787-800. doi: 10.1007/s11135-004-8107-7

Kruglanski, A. W., \& Kopetz, C. (2009). What is so special (and nonspecial) about goals?: A view from the cognitive perspective. In G. B. Moskowitz \& H. Grant (Eds.), The psychology of goals (pp. 27-55). New York: Guilford Press.

Kroenke, K., Spitzer, R. L., \& Williams, J. B. (2001). The PHQ-9. Journal of General Internal Medicine, 16(9), 606-613. doi: 10.1046/j.1525-1497.2001.016009606.x

Law, D. (2018). Goal-oriented practice. In M. Cooper \& D. Law (Eds.), Working with goals in counselling and psychotherapy (pp. 161-180). Oxford: Oxford University.

Lloyd, C., Duncan, C., \& Cooper, M. (2019). Goal Measures for psychotherapy: A systematic review of self-report, idiographic instruments. Clinical Psychology: Science and Practice. doi: 10.1111/cpsp.12281 
Locke, E. A., \& Latham, G. P. (2002). Building a practically useful theory of goal setting and task motivation - A 35-year odyssey. American Psychologist, 57(9), 705-717. doi: 10.1037//0003-066x.57.9.705

Locke, E. A., Shaw, K. N., Saari, L. M., \& Latham, G. P. (1981). Goal setting and task performance: 1969-1980. Psychological Bulletin, 90(1), 125-152. doi: 10.1037/00332909.90.1.125

Mackrill, T. (2010). Goal consensus and collaboration in psychotherapy: An existential rationale. Journal of Humanistic Psychology, 50(1), 96-107. doi: $10.1177 / 0022167809341997$

McLeod, J., \& Cooper, M. (2012). A pluralistic approach to counselling and psychotherapy for depression: Treatment manual (V.1 ed.). Dundee: University of Abertay.

McMurran, M., Cox, W. M., Whitham, D., \& Hedges, L. (2013). The addition of a goalbased motivational interview to treatment as usual to enhance engagement and reduce dropouts in a personality disorder treatment service: results of a feasibility study for a randomized controlled trial. [journal article]. Trials, 14(1), 50. doi: 10.1186/1745$6215-14-50$

Michalak, J., \& Grosse Holtfort, M. (2006). Where do we go from here? The goal perspective in psychotherapy. Clinical Psychology: Science and Practice, 13(4), 346- 365. doi: 10.1111/j.1468-2850.2006.00048.x

Miller, W. R., \& Rose, G. S. (2009). Toward a theory of motivational interviewing. American Psychologist, 64, 527-537.

Oddli, H. W., McLeod, J., Reichelt, S., \& Rønnestad, M. H. (2014). Strategies used by experienced therapists to explore client goals in early sessions of psychotherapy. European Journal of Psychotherapy \& Counselling, 16(3), 245-266. doi: $\underline{10.1080 / 13642537.2014 .927380}$ 
Papayianni, F., \& Cooper, M. (2018). Metatherapeutic communication: an exploratory analysis of therapist-reported moments of dialogue regarding the nature of the therapeutic work. British Journal of Guidance \& Counselling, 46(2), 173-184. doi: $10.1080 / 03069885.2017 .1305098$

Rodgers, B., \& Cooper, M. (2006). Proposed scoring scheme for qualitative thematic analysis: University of Strathclyde. Retrieved from https://strathprints.strath.ac.uk/id/eprint/30517

Rowan, J. (2008). Goals. BACP North London Magazine (59), 7.

Sheldon, K. M., Kasser, T., Smith, K., \& Share, T. (2002). Personal goals and psychological growth: Testing an intervention to enhance goal attainment and personality integration. Journal of Personality, 70(1), 5-31. doi: 10.1111/1467-6494.00176

Silberschatz, G. (2017). Improving the yield of psychotherapy research. Psychotherapy Research, 1, 1-13. Doi: 10.1080/10503307.2015.1076202

Smith, A. (1994). Introduction and overview. In T. J. Kiresuk, A. Smith \& J. E. Cardillo (Eds.), Goal attainment scaling: Applications, theory, and measurement (pp. 1-14). Hillsdale, NJ: Lawrence Erlbaum Associates.

Snyder, C. R., Michael, S. T., \& Cheavens, J. S. (1999). Hope as a foundation of common factors, placebos, and expectancies. In M. Hubble, B. L. Duncan \& S. D. Miller (Eds.), The Heart and Soul of Change (pp. 179-200). Washington, DC: APA.

Snyder, C. R., \& Taylor, J. D. (2000). Hope as a common factor across psychotherapy approaches: A lesson from the dodo's verdict. In Handbook of hope (pp. 89-108). Academic Press.

Spangler, W. D. (1992). Validity of questionnaire and TAT measures of need for achievement: Two meta-analyses. Psychological bulletin, 112(1), 140-154. doi: 10.1037/0033-2909.112.1.140 
Spitzer, R. L., Kroenke, K., Williams, J. B., \& Löwe, B. (2006). A brief measure for assessing generalized anxiety disorder: the GAD-7. Archives of Internal Medicine, 166(10), 1092-10

The Health Foundation. (2012). Helping people share decision making. London: The Health Foundation.

Zilcha-Mano, S. (2017). Is the alliance really therapeutic? Revisiting this question in light of recent methodological advances. American Psychologist, 72(4), 311-325. doi: $10.1037 / \mathrm{a} 0040435$ 